\title{
RANDOMIZED CONTROL TRIAL TO EVALUATE THE ROLE OF DEXMEDETOMIDINE PREMEDICATION \& KETAMINE- PROPOFOL COMBINATION FOR ATTENUATION OF POST ECT DEPRESSION AND AGITATION
}

\author{
Roopesh Kumar'1, Chavi Sethi², Prashasti Saxena ${ }^{3}$, Aman Singh ${ }^{4}$
}

1 Professor and HOD, Department of Anaesthesia, MLB Medical College, Jhansi, Uttar Pradesh, India.

${ }^{2}$ Assistant Professor, Department of Anaesthesia, MLB Medical College, Jhansi, Uttar Pradesh, India.

${ }_{3}^{3}$ Postgraduate Student, Department of Anaesthesia, MLB Medical College, Jhansi, Uttar Pradesh, India.

${ }^{4}$ Resident, Department of Surgery, TNMC, Mumbai, India.

\section{BACKGROUND}

ABSTRACT

Electroconvulsive Therapy is associated with hyperdynamic response which can lead to cardiac dysrhythmias, myocardial ischemia or infarction. Dexmedetomidine is alpha-2 agonist with anxiolytic, sedative, sympatholytic and analgesic effects which can attenuate the hyperdynamic response and also reduce post ictal agitation in patients. Ketamine is considered in ECT for preserving cognitive function and antidepressant effects. Side effects of ketamine like hallucinations and hyperdynamic response are relieved by combining propofol which is associated with faster emergence and better psychomotor recovery.

\section{METHODS}

100 patients were randomly allocated into 2 groups of 46 each. Group A- dexmedetomidine $(0.5 \mu \mathrm{g} / \mathrm{kg})$ infusion premedication with ketamine-propofol (10 mg/kg each, 1:1 combination); Group B- normal saline infusion prior to ketamine-propofol (10 mg/kg each 1:1). Patients undergo ECT using ketamine-propofol according to randomly allocated groups and pre and post ECT agitation and depression scores were calculated and compared.

\section{RESULTS}

Out of 92 cases done, (group A-46, group B-46), best results regarding hemodynamic stability and recovery parameters were achieved in Group A without any significant side effects.

\section{CONCLUSIONS}

Ketofol-dexmedetomidine combination for ECT is associated with a longer mean seizure time, effective antidepressive effect following $1^{\text {st }}$ session, lower incidence of agitation, more patient satisfaction, and acceptable decrease in heart rate and blood pressure when compared to ketofol and without any significant side effects.

HOW TO CITE THIS ARTICLE: Kumar R, Sethi C, Saxena P, et al. Randomized control trial to evaluate the role of dexmedetomidine premedication \& ketamine- propofol combination for attenuation of post ECT depression and agitation. J. Evolution Med. Dent. Sci. 2019;8(16):1301-1306, DOI: 10.14260/jemds/2019/290

\section{BACKGROUND}

Electroconvulsive therapy (ECT), formerly known as electroshock therapy, and often referred to as shock treatment, is a psychiatric treatment in which seizures are electrically induced in patients to provide relief from psychiatric disorders. The ECT procedure was first conducted in 1938 and is the only currently used form of shock therapy in psychiatry. ECT is often used with informed consent as a last line of intervention for major depressive disorder, mania, bipolar disorders and schizophrenia. An electric current is applied to the brain via trans cutaneous electrodes which induce a tonic clonic seizure comprising tonic phase for 10-15 $\mathrm{s}$ and clonic phase for $30-60 \mathrm{~s}^{1}$

Much of the stigma attached to ECT is based on early treatments in which high doses of electricity were administered without anaesthesia, leading to memory loss,

'Financial or Other Competing Interest': None.

Submission 04-03-2019, Peer Review 11-04-2019,

Acceptance 17-04-2019, Published 22-04-2019.

Corresponding Author:

Dr. Chavi Sethi,

J-41, Ajay Enclave,

Mandi Road,

Jhansi-284002,

Uttar Pradesh, India.

E-mail:dr_chavi@gmail.com

DOI: $10.14260 /$ jemds $/ 2019 / 290$ fractured bones etc. ECT is also associated with hyperdynamic response due to increased concentrations of catecholamines causing rise in blood pressure and heart rate. This acute hyperdynamic response may lead to cardiac dysrhythmias, myocardial ischemia and infarction. ${ }^{2}$

Since combination of ECT with general anaesthesia has emerged these side effects have been mitigated. The goals during general anaesthesia during ECT is to get rapid loss of unconsciousness, avoidance of gross movements, minimal interference with seizure activity, amnesia and prompt recovery of spontaneous ventilation and consciousness. The choice of anaesthetic agents may influence seizure quality and duration, and haemodynamic, and recovery parameters. ${ }^{3}$

To attenuate hyperdynamic response during ECT, many pharmacological agents such as beta blockers, alpha-2 agonists, vasodilators and local anaesthetics were tried.

Dexmedetomidine is a potent as well as highly selective alpha-2 agonist with sedative, sympatholytic and analgesic effect. It acts at locus coeruleus and spinal cord to exert anxiolytic and sedative effects without respiratory depression when given as premedication prior to general anesthesia 4 Moreover, stimulation of alpha- 2 receptors decreases calcium entry in nerve terminals resulting in inhibitory effect on neurotransmitter release. This facilitates analgesia and attenuates stress response during ECT. ${ }^{5}$

For ECT, the optimal seizure duration remains unclear. An adequate seizure in ECT is defined as one lasting longer than 
30 s. Too short $(<10$ s) or too long $(>120$ s) seizures may reduce clinical efficacy ${ }^{6}$. Emergence agitation (excitement, restlessness, and panic) may occur in some patients after ECT ${ }^{7}$. Dexmedetomidine is very effective in management of emergence agitation following ECT.

Anaesthetic agent for ECT includes ketamine, propofol, dexmedetomidine, thiopentone, methohexitone, etomidate, and sevoflurane 8 .

Ketamine is N-methyl D- aspartate (NMDA) receptor antagonist with seizure inducing properties and increases seizure duration ${ }^{9}$.

Ketamine is also considered as neuroprotective during ECT preserving cognitive function by preventing excitotoxic neuronal damage (Caused by glutamate action on NMDA receptors). ${ }^{10}$

Propofol is GABA chloride channel agonist which facilitates loss of consciousness by release of inhibitory neurotransmitter in brain. Propofol is associated with less nausea vomiting, aster emergence, better psychomotor recovery and early cognitive recovery ${ }^{11}$.

Common adverse effects of ketamine like hallucinations and hyperdynamic response in the form of increased HR and blood pressure are relieved by propofol when used along with it. ${ }^{12}$ Ketamine when used in combination with propofol decreases its consumption and preserves haemodynamic stability. The mean recovery times from ketamine-propofol sedation is shorter than IV ketamine alone and longer than IV propofol alone. So role of dexmedetomidine in combination with ketamine and propofol needs evaluation in terms of hemodynamic parameters \& seizure duration during ECT. ${ }^{13}$ This combination can also be used to assess post ECT agitation and depression in patients.

\section{Aims and Objectives}

The Aims and Objectives of this Study are-

- To assess the hemodynamic changes during ECT i.e.

- Mean arterial pressure

- Pulse oximetry

- Heart rate

- Continuous ECG monitoring

- To evaluate role of dexmedetomidine to attenuate postECT hyperdynamic response

- Secondary outcomes of dexmedetomidine studied in terms of its effect on motor seizure duration, recovery parameters and post ECT agitation, patient sedation and satisfaction scores 1 using following scores:

- Agitation score

- Patient satisfaction score

- Hamilton depression rating scale.

\section{METHODS}

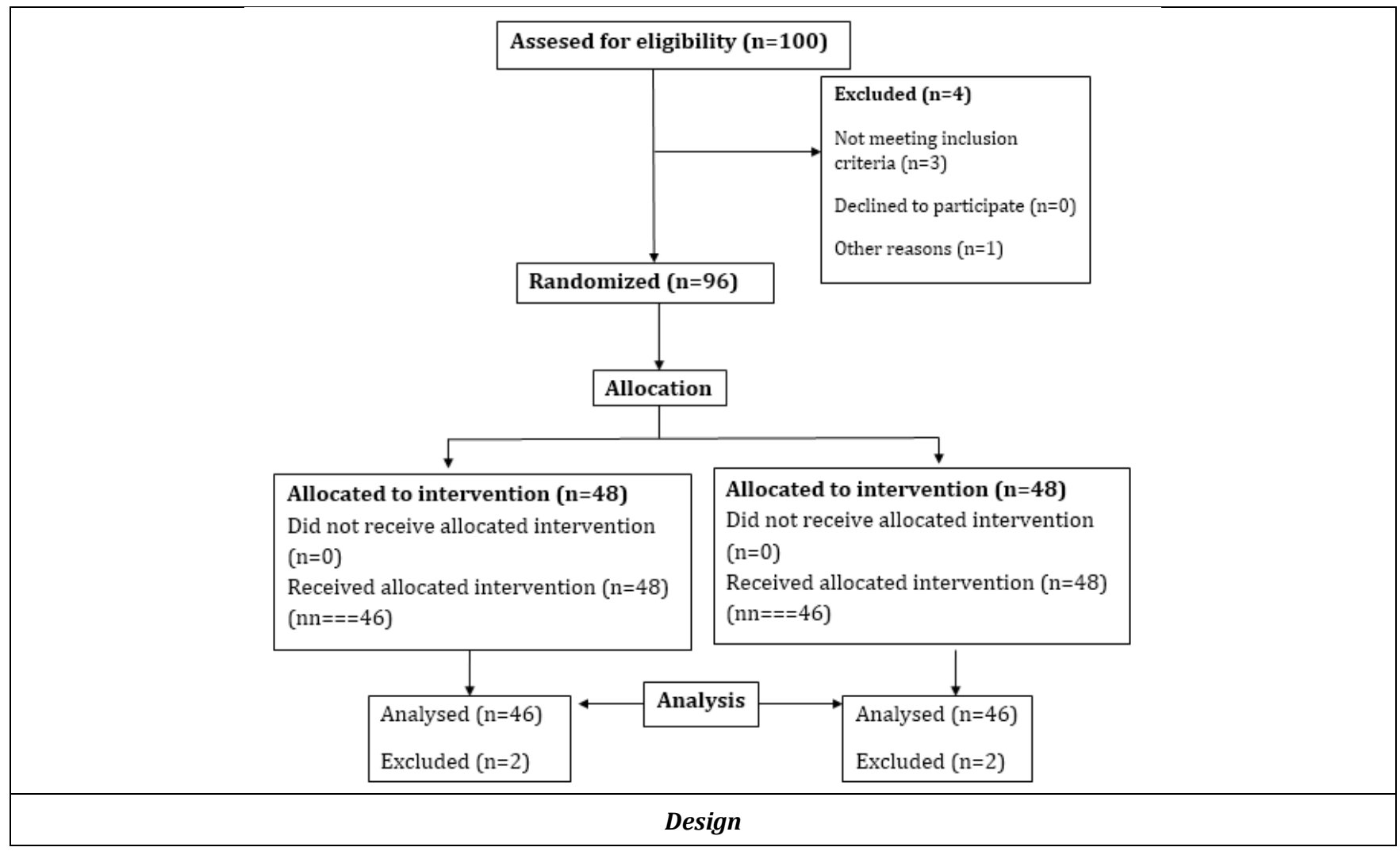

This is a randomized controlled double blinded study. The study was conducted in Department of Anaesthesiology and Critical Care and Department of Psychiatry, M.L.B. Medical College, Jhansi (UP) in patients diagnosed with major depressive disorders are scheduled for ECT.
Following the approval from ethical committee, patients scheduled for ECT, ASA I and II, age between 18-60 years, without a history of cardiovascular disease, no history of using beta blocker drugs or narcotic usage and should not be sensitive to any drug used in the study were included. 


\section{Exclusion Criteria}

- Baseline bradycardia (HR<50 beats/min)

- Patients with other psychiatric disorders

- Patients with serious physical disease such as cardiovascular and cerebrovascular disorders.

- Patients with intracranial hypertension, cerebral aneurysm or respiratory tract disease.

- Patients with glaucoma, previous fracture or history of seizures

- Patients with hemodynamic instability or pregnancy.

\section{Sample Size and Allocation}

Selection of cases: A total of 100 cases were selected based on the convenience of the study out of which 92 patients fulfilled the inclusion criteria were included in this study, 8 patients were excluded later on for various reasons listed ahead.

Study patients were randomly assigned in the following two groups each containing 46 patients Group A and 46 patients Group B.

- Group A- Patients received intravenous dexmedetomidine premedication with ketaminepropofol combination

- Group B- Patients received intravenous normal saline prior to ketamine-propofol combination

Pre procedure visit was conducted one day before ECT to take detailed history and for general and systemic examinations of the cardiovascular, respiratory and central nervous system examinations. In addition, airway was also assessed. The guardians of the patients were explained the indication, risks and benefits of dexmedetomidine along with ketamine-propofol combination for ECT.

Routine lab investigations like complete haemogram, ECG, serum creatinine and blood sugar were carried out. Patients were assessed for depression by a psychiatrist unaware of the anaesthetic study groups using Hamilton Depression Rating Scale.

Chronic antidepressants and other antipsychotic medications were continued till the day of the procedure. The patients were kept nil by mouth for at least 8 hours and encouraged to empty their bladder before ECT.

The preparation of patients in each group is standardized as much as possible. Patients were taken to ECT room where standard monitoring like ECG, pulse oximeter probe and NIBP were placed in supine position with a pillow under head. A 20G IV canula was secured and Ringer Lactate was started through it.

After premedication with $0.5 \mathrm{mg}$ intravenous atropine sulphate $0.5 \mu \mathrm{g} / \mathrm{kg}$ dexmedetomidine (diluted to $10 \mathrm{ml}$ with $0.9 \%$ normal saline) for group I or $10 \mathrm{ml}$ normal saline for group II was infused iv slowly over 10 mins before induction of anaesthesia by an anaesthesiologist not involved in recording of data.

Patients were preoxygenated with $100 \%$ oxygen and ketamine propofol mixture of $10 \mathrm{mg} / \mathrm{ml}$ ketamine and 10 $\mathrm{mg} / \mathrm{ml}$ propofol mixed in a $20 \mathrm{ml}$ syringe was given slowly $(20$ mg over 10 seconds) until the patient no longer responds to his/ her name called loudly. Additional drug was given in 10 $\mathrm{mg}$ increments if the responsiveness to verbal command was not lost in 60 seconds of drug administration. The required total dose of inducing drug was recorded.
Succinylcholine in a dose of $0.5 \mathrm{mg} / \mathrm{kg}$ was administered after induction of anaesthesia with ketamine-propofol combination and manual ventilation performed with face mask using $100 \%$ oxygen at a flow rate of $8 \mathrm{~L} / \mathrm{min}$. A bite block was used to protect patient's teeth, lips and tongue.

A suprathreshold electrical stimulus was given via bifrontotemporal electrodes and ventilation was assisted with oxygen during the procedure.

Various parameters both during the ECT and after patient was fully awake were documented by a medical assistant. The anaesthetist, patients and assessor who analysed the data using various statistical tests were all blinded to the study.

\section{Variables Assessed}

- Primary - To evaluate the effect of Dexmedetomidine premedication \& Ketamine- Propofol combination for attenuation of post ECT Depression and Agitation using:

- Agitation Score.

- Patient Satisfaction Score.

- Hamilton Depression Rating Scale.

- $\quad$ Secondary - to assess hemodynamic changes during ECT.

- Mean arterial pressure.

- Heart rate.

- Pulse oximetry.

- Continuous ECG monitoring

- Motor seizure duration.

- Time taken to recover after ECT in terms of return of spontaneous ventilation, eyes opening and following commands.

- Any complication.

Bradycardia is taken as heart rate $<60$ beats/min, tachycardia is taken as heart rate $>100$ beats $/ \mathrm{min}$.

Hypotension is taken as mean arterial pressure $<60$ $\mathrm{mmHg}$; hypertension is defined as mean arterial pressure $>120 \mathrm{mmHg}$.

Respiratory depression is defined as respiratory rate $<10$ breaths/min. Hypoxemia is defined as oxygen saturation (Sp02) of $90 \%$ or less.

The duration of motor seizure is defined as time from beginning of ECT to cessation of tonic clonic activity in isolated arm.

The time from the end of succinylcholine administration until spontaneous breathing, eye opening and obeying commands were recorded.

\section{Data Analysis}

- $\quad$ SPSS software version 16

- $\quad$ Following tests were used;

- Independent $t$ test (Quantitative data)

A $t$ test is a type of inferential statistic tool used to determine if there is a significant difference between the mean of two groups ${ }^{14}$.

- $\quad$ Chi square test (Qualitative data)

Independence test evaluates if two categorical values are related in any way.

- $\quad \mathrm{p}<0.05$ was considered statistically significant 
RESULTS

\begin{tabular}{|c|c|}
\hline Number of patients satisfying inclusion criteria & 100 \\
\hline Number of patients excluded & 8 \\
\hline Total number of patients included in the study & 92 \\
\hline \multicolumn{2}{|c|}{ Table 1. Total Number of Patients } \\
\hline Table showing total patients included and excluded in the \\
study.
\end{tabular}

\begin{tabular}{|c|c|c|c|c|}
\hline Age (in Yrs.) & Group A & $\mathbf{\%}$ & Group B & \% \\
\hline $18-30$ & 04 & $8.69 \%$ & 12 & $20.08 \%$ \\
\hline $31-40$ & 14 & $30.43 \%$ & 05 & $10.86 \%$ \\
\hline $41-50$ & 09 & $19.56 \%$ & 13 & $28.26 \%$ \\
\hline $51-60$ & 19 & $41.30 \%$ & 16 & $34.78 \%$ \\
\hline
\end{tabular}

Table 2. Distribution of Patients According to Age

Table showing \% distribution of patients in the study according to age.

\begin{tabular}{|c|c|c|c|}
\hline & Group A & Group B & p value \\
\hline Mean & 44.95 & 43.08 & \multirow{2}{*}{0.4588} \\
\hline SD & \pm 11.041 & \pm 12.988 & \\
\hline \multicolumn{3}{|c|}{ Table 3. Mean Age of Patients } \\
\hline \multicolumn{3}{|c|}{ Table showing mean patients according to age in both } \\
groups. \\
\hline
\end{tabular}

\begin{tabular}{|c|c|c|c|c|}
\hline Gender & Group A & Group A \% & Group B & Group B \% \\
\hline Males & 10 & $21.73 \%$ & 33 & $71.73 \%$ \\
\hline Females & 36 & $78.26 \%$ & 13 & $28.26 \%$ \\
\hline
\end{tabular}

Table 4. Gender Distribution in Study Group

Table showing gender distribution in the study.

\begin{tabular}{|c|c|c|c|}
\hline & Group A & Group B & p Value \\
\hline Mean & 21.30 & 21.56 & \multirow{2}{*}{0.1871} \\
\hline SD & \pm 0.952 & \pm 0.924 & \\
\hline
\end{tabular}

Table 5. Mean HDR Score (Baseline) in Study Group

Table showing baseline mean HDR score in the study group.

\begin{tabular}{|c|c|c|c|}
\hline & Group A & Group B & p Value \\
\hline Mean & 98.93 & 98.86 & \multirow{2}{*}{0.6498} \\
\hline SD & \pm 0.734 & \pm 0.740 & \\
\hline \multicolumn{4}{|c|}{ Table 6. Mean SpO S $_{2}$ in Study Group } \\
\hline \multicolumn{3}{|c|}{ Table showing mean SpO2 in patients of both groups. } \\
\hline
\end{tabular}

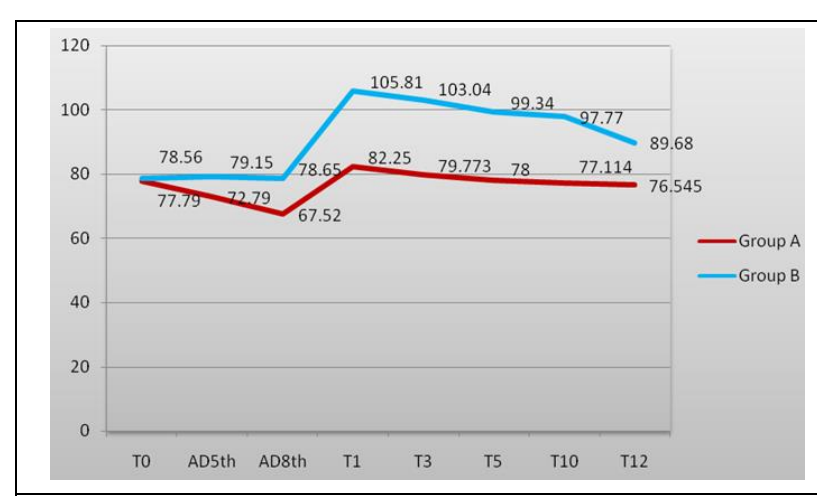

Table 7. Mean Pulse Rate in Study Group

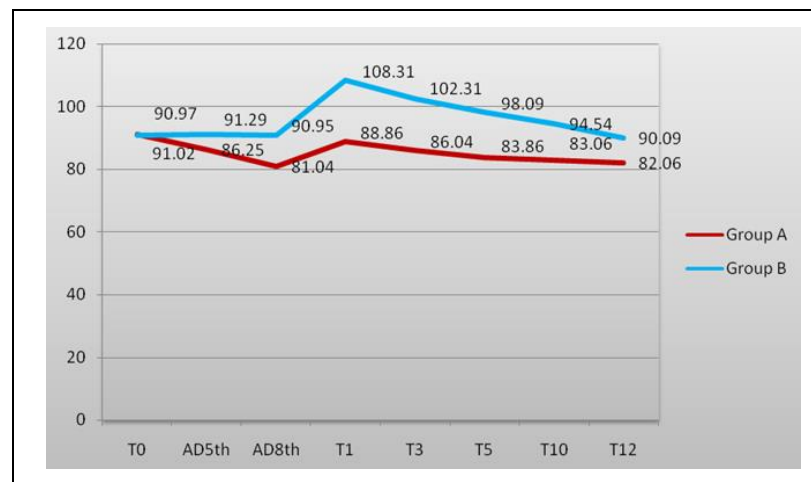

Table 8. Mean Arterial Pressure in Study Group

\begin{tabular}{|c|c|c|c|}
\hline & Group A & Group B & p Value \\
\hline Mean & 35.13 & 31.04 & 0.0001 \\
\hline SD & \pm 1.483 & \pm 3.463 & \\
\hline \multicolumn{3}{|c|}{ Table 9. Mean Seizure Duration (in Seconds) in Study } \\
Group \\
\hline
\end{tabular}

\begin{tabular}{|c|c|c|c|c|c|}
\hline \multirow{2}{*}{ Pulse rate } & \multicolumn{2}{|c|}{ Group A } & \multicolumn{2}{c|}{ Group B } & \multirow{2}{*}{ p Value } \\
\cline { 2 - 6 } & Mean & SD & Mean & SD & \\
\hline $\begin{array}{c}\text { Spontaneous } \\
\text { respiration }\end{array}$ & 4.5 & \pm 0.499 & 4.45 & \pm 0.495 & 0.6306 \\
\hline Open eyes & 6.97 & \pm 0.765 & 6.93 & \pm 0.704 & 0.7947 \\
\hline $\begin{array}{c}\text { Obey } \\
\text { command }\end{array}$ & 10.97 & \pm 0.834 & 11.31 & \pm 0.819 & 0.0516 \\
\hline
\end{tabular}

Table 10. Recovery Parameters (in Min)

\begin{tabular}{|c|c|c|c|c|}
\hline \multirow{2}{*}{ Parameters } & \multicolumn{2}{|c|}{ Group A } & \multicolumn{2}{c|}{ Group B } \\
\cline { 2 - 5 } & No & $\mathbf{\%}$ & No & \% \\
\hline 1 Sleeping & 44 & $95.65 \%$ & 36 & $78.46 \%$ \\
\hline 2 Awake and calm & 02 & $4.34 \%$ & 07 & $15.21 \%$ \\
\hline 3 Irritable and crying & 00 & $00.00 \%$ & 03 & $6.52 \%$ \\
\hline
\end{tabular}

Table 11. Agitation Score in Study Group

\begin{tabular}{|c|c|c|c|}
\hline & Group A & Group B & p Value \\
\hline Mean & 1.04 & 1.27 & \multirow{2}{*}{0.0125} \\
\cline { 1 - 3 } SD & \pm 0.203 & \pm 0.577 & \\
\cline { 1 - 1 } \multicolumn{2}{|c|}{ Table 12. Mean Agitation Score in Study Group } \\
\hline
\end{tabular}

\begin{tabular}{|c|c|c|c|c|}
\hline \multirow{2}{*}{ Parameters } & \multicolumn{2}{|c|}{ Group A } & \multicolumn{2}{c|}{ Group B } \\
\cline { 2 - 5 } & No & \% & No & $\%$ \\
\hline 1 Pleased and calm patient & 44 & $95.65 \%$ & 38 & $82.60 \%$ \\
\hline 2 Patient has no complaints & 02 & $4.34 \%$ & 05 & $10.86 \%$ \\
\hline $\begin{array}{c}\text { 3 Patient has some } \\
\text { complaints }\end{array}$ & 00 & $00.00 \%$ & 02 & $4.34 \%$ \\
\hline $\begin{array}{c}\text { 4 Patient complained } \\
\text { treatment was unpleasant }\end{array}$ & 00 & $00.00 \%$ & 01 & $2.17 \%$ \\
\hline \multicolumn{4}{|c|}{ Table 13. Patients Satisfaction Score in Study Group } \\
\hline
\end{tabular}

\begin{tabular}{|c|c|c|c|}
\hline & Group A & Group B & p Value \\
\hline Mean & 1.04 & 1.27 & \multirow{2}{*}{$\mathbf{0 . 0 0 2 2 4}$} \\
\hline SD & \pm 0.203 & \pm 0.640 & $\mathbf{0}$ \\
\cline { 1 - 3 } &
\end{tabular}

Table 14. Mean Patients Satisfaction Scorein Study Group

\begin{tabular}{|c|c|c|c|c|}
\hline \multirow{2}{*}{ Parameters } & \multicolumn{2}{|c|}{ Group A } & \multicolumn{2}{c|}{ Group B } \\
\cline { 2 - 5 } & Mean & SD & Mean & SD \\
\hline Pre ECT (Basal) & 21.30 & \pm 0.952 & 21.56 & \pm 0.924 \\
\hline 1 day after ECT & 13.27 & \pm 1.617 & 16.15 & \pm 1.238 \\
\hline Table 15. Comparison of Baseline and Follow-Up HDR \\
Scores
\end{tabular}




\section{DISCUSSION}

Electroconvulsive Therapy with general anaesthesia has emerged beneficial to manage patients with major depressive disorders effectively. Ketamine is phencyclidine derivative which binds non competitively to phencyclidine recognition site N-Methyl-D-aspartate (NMDA) receptors and inhibits their activation via glutamate neurotransmitter and also decreases presynaptic release of glutamate. 15 While Propofol exerts its sedative hypnotic effect through GABAA interaction thereby increasing the duration of GABA activated opening of chloride channel with resulting hyperpolarization of cell membranes. Ketamine causes dissociation of the limbic system with the cerebral cortex thus inheriting remarkable antidepressant properties. The side effects of ketamine include sympathetic stimulation, hallucinations as opposed to propofol which decreases blood pressure by reducing systemic vascular resistance. Combination of anaesthetic agents like ketamine and propofol have a short half-life with rapid onset and recovery, maintain haemodynamic stability and have no interference with seizure duration or seizure threshold. Propofol is quite comparable to ketamine in ultimate antidepressant efficacy of ECT. Furthermore, combining propofol with ketamine (ketofol) retains the early antidepressant property of latter, while reducing the adverse effects like hallucinations and sympathetic stimulation. This was in accordance with Wang X et al. In Effects of propofol and ketamine as combined anaesthesia for electroconvulsive therapy in patients with depressive disorder.

Okamoto N, Nakai T et al. in Rapid antidepressant effect of ketamine anaesthesia during electroconvulsive therapy of treatment-resistant depression: Comparing ketamine and propofol anaesthesia have discussed the improvement of patients with depressive disorders using ketamine. ${ }^{3}$

The reference has also been taken from Comparison of the effect of intravenous anesthetics used for anesthesia during electroconvulsive therapy on the hemodynamic safety and the course of ECT.Wojdacz R, Święcicki Ł, Antosik-Wójcińska A. Psychiatry Pol.

Dexmedetomidine is a potent $\alpha_{2}$-adrenergic agonist with unique properties of sympatholysis, sedation and analgesia that make it ideally suited for ECT to blunt the acute hyperdynamic response associated with it and its sedative effect helps in reducing agitation and improving satisfaction in patients who otherwise complain about ECT as an unpleasant experience. 16

Adding dexmedetomidine premedication along with ketamine propofol combination (Ketofol-dex) has added antidepressive effect following first ECT session due to improved seizure duration in a calm patient. Ketofol-dex combination has also been found to be advantages in the form of lower incidence of agitation, more patient satisfaction and acceptable decrease in heart rate and blood pressure when compared to inducing agent alone and without any significant side effects ${ }^{17}$. The results were comparable to the study Dexmedetomidine blunts acute hyperdynamic responses to electroconvulsive therapy without altering seizure duration in Anaesthesiologica Scandinavia 2008; 90:422-4 where the benefits of adding alpha- 2 agonist as premedication was discussed.

The demographic data (age, sex) was comparable in both the groups. Mean age in group A was $44.95 \pm 11.041$ and in group B was $43.08 \pm 12.988$. Female ratio was $2: 1$ in both groups and thus comparable.

One of the supposed benefits of adding $\alpha 2$ agonist like dexmedetomidine as premedication prior to ECT was to contain the sudden hyperdynamic response associated with seizure. This was definitely seen in group A as improved hemodynamic parameters like pulse rate (mean $82.25 \pm 4.606$ ) and Mean arterial pressure (mean $88.86 \pm 1.577$ ). This was sharply in contrast to mean pulse rate $(105.81+4.881)$ and mean arterial pressure $(108.31 \pm 1.305)$ in group B just after seizure. Thus, adding dexmedetomidine as premedication reduces the acute rise in hemodynamic parameters ${ }^{18}$ which have minimized the risk of myocardial ischemia and infarction just after seizure in ECT.

The primary outcome of our current study showed that dexmedetomidine premedication along with ketamine propofol combination (ketofol-dex) lowered incidence of agitation in patients after ECT. $95.65 \%$ and $4.34 \%$ persons had agitation score 1 and 2 in group A as compared to group B where score $1,2,3$ was $78.46 \%, 15.21 \%$ and $6.5 \%$ respectively. This was in accordance to study of Mizrak A, Koruk $\mathrm{S}$ et al. Premedication with dexmedetomidine and midazolam attenuates agitation after electroconvulsive therapy.

Even under general anaesthesia many patients complain ECT as an unpleasant experience. This study also showed that adding dexmedetomidine premedication reduced patients' complaints and improved their satisfaction after ECT as seen in Satisfaction Score of 1 in $95.65 \%$ of Group A rather than $86.60 \%$ in group B. This was found to be statistically significant.

Similar results were obtained in study of Shams T, ElMasry R. Ketofol-dexmedetomidine combination in ECT: A punch for depression and agitation.

Hamilton depression rating score was calculated 1 day prior to ECT in patients with depression and 24 hours after ECT. Using ketamine-propofol as inducing agents for ECT for patients with major depression saw reduction in HDR scores in both groups but above than that; improvement in HDR scoring was much more and highly significant in group A (by 8-10 points) than in group $B$ (5-6 points). This may be attributed to improved seizure duration in group $\mathrm{A}$ and thus better outcome.

The limitation of this study is that it does not include other psychiatric disorders undergoing ECT.

Adverse effects of dexmedetomidine like bradycardia and hypotension were seen in 8 patients who were then excluded from the study.

In this study, the demographic data in both groups was comparable with no significant difference in age, sex etc. The mean agitation score in group A was $1.04 \pm 0.203$ as compared to 1.27 in group B. This was found to be highly significant $(\mathrm{p}<0.05)$. The number of patients with agitation score 1 and 2 was $95.65 \%$ and $4.34 \%$ respectively in group A while it was $82.60 \%$ \& $10.86 \%$ in group B along with $4.34 \%$ and $2.17 \%$ agitation score of 3 and 4 . Patient satisfaction score was significantly higher in group A $1.04 \pm 0.203$ as compared to group B $1.27 \pm 0.640(\mathrm{p}<0.05)$.

Depression Scoring improved significantly 1 day after ECT in group A than in group B (10 points). Also there was significant decrease of MAP and PR just after ECT (T1) in group A when compared to group $B$, in a clinically acceptable range 
$(\mathrm{p}<0.01)$.Total Seizure duration improved significantly in group A (35.13 \pm 1.48$)$ as compared to group B (31.04 \pm 3.46$)$ but without affecting recovery in group $A$ than $B$.

- Adverse reactions: 2 patients who were included in the study developed bradycardia after administering premedication and procedure therefore had to be abandoned.

- Limitation: Patients with other psychiatric disorders were not included.

\section{CONCLUSIONS}

Ketofol-dexmedetomidine combination for ECT is associated with a longer mean seizure time, effective anti-depressive effect following $1^{\text {st }}$ session, lower incidence of agitation, more patient satisfaction, and acceptable decrease in heart rate and blood pressure when compared to ketofol, and without any significant side effects.

\section{REFERENCES}

[1] Augustoides JG, Greenblatt E, Abbas MA, et al. Clinical approach to agitation in electroconvulsive therapy: case report and literature review. J ECT 2002;18(4):213-7.

[2] Logan CJ, Stewart JT. Treatment of post electroconvulsive therapy delirium and agitation with donepezil. JECT 2007;23(1):28-9.

[3] Okamoto $N$, Nakai $T$, Sakamoto $K$, et al. Rapid antidepressant effect of ketamine anesthesia during ECT of treatment - resistant depression: Comparing ketamine and propofol anesthesia. J ECT 2010;26(3):223-7.

[4] Mizrak A, Koruk S, Ganidagli S, et al. Premedication with dexmedetomidine and midazolam attenuates agitation after electroconvulsive therapy. J Anesth 2009;23(1):610 .

[5] Shams T, El-Masry R. Ketamine Propofol combination punch for depression and agitation. Indian J Anaesth 2014;58(3):275-80.

[6] Geretsegger C, Rochowanski E, Kartnig C, et al. Propofol and methohexital as anesthetic agents for electroconvulsive therapy (ECT): a comparison of seizure-quality measures and vital signs. J ECT 1998;14(1):28-35.

[7] Cohen MB, Stewart JT. Treatment of post ECT agitation with dexmedetomidine. J ECT 2013;29(2):e23-e4.
[8] Uppal V, Dourish J, Macfarlane A. Anaesthesia for electroconvulsive therapy. CEACCP 2010;10(6):192-6.

[9] Timm C, Linstedt U, Weiss T, et al. Sympathomimetic effects of low-dose S (+)-ketamine. Effect of propofol dosage. Anaesthesist 2008;57(4):338-46.

[10] Kranaster L, Kammerer-Ciernioch J, Hoyer C, et al. Clinically favourable effects of ketamine as an anaesthetic for electroconvulsive therapy: a retrospective study. European Arch Psychiatry Clin Neuroscience 2011;261(8):575-82.

[11] Okamoto N, Nakai T, Sakamoto K, et al. Rapid antidepressant effect of ketamine anesthesia during electroconvulsive therapy of treatment-resistant depression: comparing ketamine and propofol anesthesia. J ECT 2010;26(3):223-7.

[12] Wang X, Chen Y, Zhou X, et al. Effects of propofol and ketamine as combined anesthesia for electroconvulsive therapy in patients with depressive disorder. J ECT 2012;28(2):128-32.

[13] Begec Z, Toprak HI, Demirbilek S, et al. Dexmedetomidine blunts acute hyperdynamic responses to electroconvulsive therapy without altering seizure duration. Acta Anaesthesiol Scand 2008;52(2):302-6.

[14] Moher D, Hopewell S, Schulz KF, et al. CONSORT 2010 Explanation and Elaboration: Updated guidelines for reporting parallel group randomised trials. J Clin Epidemiol 2010;63(8):e1-37.

[15] Zarate CA Jr, Singh JB, Carlson PJ, et al. A randomized trial of an N-methyl-D-aspartate antagonist in treatment-resistant major depression. Arch Gen Psychiatry 2006;63(8):856-64.

[16] Grant SA, Breslin DS, MacLeod DB, et al. Dexmedetomidine infusion for sedation during fiberoptic intubation: a report of three cases. J Clin Anesth 2004;16(2):124-6.

[17] Levänen J, Mäkelä ML, Scheinin H. Dexmedetomidine premedication attenuates ketamine-induced cardiostimulatory effects and postanesthetic delirium. Anesthesiology 1995;82(5):1117-25.

[18] Sharan R, Bala N, Attri JP, et al. A comparison of dexmedetomidine with propofol to attenuate the hemodynamic stress responses after electroconvulsive therapy. Indian J Psychiatry 2017;59(3):366-9. 